\title{
Attitudes and Perspectives of Older Adults on Technologies for Assessing Frailty in Home Settings: A Focus Group Study
}

Chao Bian ( $\nabla$ chao.bian@mail.utoronto.ca )

University of Toronto

Bing Ye

University of Toronto

Anna Hoonakker

Utrecht University

Alex Mihailidis

University of Toronto

\section{Research Article}

Keywords: Frailty, Assessment, Technology, Sensors, In-Home Health Monitoring, Attitudes, Focus Group

Posted Date: December 17th, 2020

DOl: https://doi.org/10.21203/rs.3.rs-126089/v1

License: (a) (i) This work is licensed under a Creative Commons Attribution 4.0 International License.

Read Full License 


\section{Abstract}

Background The rapid development of technology such as sensors and artificial intelligence in recent years enables monitoring frailty criteria to assess frailty early and accurately from a remote location such as a home. However, research shows technologies being abandoned or rejected by users due to a lack of compatibility and consumer involvement with the technologies. This study aims to understand older adult's perceptions and preferences of technologies that can be potentially used to assess frailty in home settings.

Methods This study is a qualitative study in which data were collected through focus group interviews. We recruited 15 older participants. Questions were asked to achieve the goal of understanding their attitudes on the technologies. These questions include 1) the concerns or barriers of installing and using the presented technology in daily life at home, 2) the reasons participants like or dislike a particular technology, 3) what makes a particular technology more acceptable, and 4) participants' preferences in choosing technologies. Data were transcribed, coded and categorized, and finally synthesized to understand the attitudes towards presented technologies.

Results A total of 15 older adults aged 65 and older were recruited. Three focus group sessions were conducted with five participants in each session. In the findings, the attitudes and perspectives of participants on the technologies for assessing frailty were presented in four areas: A) general attitude towards using the technologies, B) concerns about the technologies, C) existing living habits or patterns related to using the technologies, and D) constructive suggestions related to the technologies.

Conclusions This study focuses on understanding the attitudes and perceptions of older adults on several technologies that could potentially be used to assess frailty in home settings. Participants generally have positive attitudes towards allowing the technologies to be installed and used at their home. Some technologies were found to be more acceptable if used under certain conditions. However, questions and concerns still remain. The study also found the living habits or patterns of older adults could affect the design and use of technology. Lastly, many valuable suggestions have been made by participants.

\section{Background}

Frailty is a clinical condition which plays a role in the aging process. It is defined as a "medical syndrome with multiple causes and contributors that is characterized by diminished strength, endurance, and reduced physiologic function that increases an individual's vulnerability for developing increased dependency and/or death" (1). Based on 21 cohorts involving 61,500 participants, on average, $10.7 \%$ of community-dwelling older adults are frail and another $41.6 \%$ are pre-frail (2). It is important to understand frailty because its effect will create greater complexity in treatment choices, care planning, and costs of care (3). Identification and early detection of frailty will enable personalized care by selecting an appropriate treatment plan, which could possibly reverse the frailty (4-6). Current clinical assessments 
have limitations such as relying on well-trained clinicians to interpret results or are too complex to be administered (3). As frailty is a dynamic and chronic condition, repeated assessment is needed. Technology could be the solution as healthcare resources become limited to the aging population.

A systematic review that synthesized technologies for assessing frailty in home settings found increasing numbers of research trials in recent years on using sensors and artificial intelligence for monitoring criteria related to frailty such as walking speed, muscle strength, physical activities, etc., in order to assess frailty early and accurately from a remote location such as a home (7). However, research shows technologies being abandoned or rejected by users due to a lack of compatibility and consumer involvement with the technologies $(8,9)$. To design assistive and intelligent technologies that are useful and usable for healthy and frail elderly people, it is necessary to know and understand the users. Thus, meeting their needs and requirements. This can be done by working with a user-centered approach. A user-centered approach incorporates user requirements, user goals and user tasks into the design process $(10,11)$. The success of this research project depends on older adults being able to use the proposed technology. As such, it is necessary to research and incorporate the users in the process of designing this new solution.

This starts with gaining insights in the user's preferences, needs, wishes and attitudes regarding health monitoring. Involving the targeted audience in the design process before creating the toolkit will allow us to select technologies for the frailty toolkit which are appreciated by the target population. Focus group discussions are a frequently used method to obtain knowledge, perspectives, and attitudes of people about issues (9). In health services research, the primary goal of focus groups is to elicit information to answer research questions (12).

Multiple studies researching the use of health technologies use focus groups to reveal usability issues within these technologies (13-16). Several focus group studies have given great insights into user's perceptions about health monitoring (17-19). An example of a focus group study in Sweden exploring the perceptions of patients with Parkinson's disease regarding the use of wearable technology for disease monitoring and management (20). Another example of a focus group study involving older adults and smart home technologies shows this method being valuable to gain insights into improving these technologies. This study resulted in several recommendations for the visualisations used in health monitors (21).

\section{Research Aim}

The aim of this study is to understand older adult's perceptions and preferences on technologies that can be potentially used to measure the criteria of frailty in home settings. The results will help guide the design of a technology toolkit for assessing and monitoring frailty at home.

\section{Methods}




\section{Design}

This study is a qualitative study in which data were collected through focus group interviews. Focus groups can provide valuable information for developing new technologies (19). We conducted three focus group sessions with older adults to evaluate their perceptions and preferences on multiple different types of technologies in the context of frailty and assessing frailty using technologies in home settings. Ethical approval was obtained from the Research Ethics Board at the University of Toronto.

\section{Recruitment and Participants}

The inclusion criteria include:

- Be aged at least 65 years and/or older

- Be fluent in English

- Cognitively able to participate in the study for up to 90 minutes

- Cognitively able to provide informed consent as determined by the study protocol

We intended to include both participants who have or have not experienced any physical decline while aging. Therefore, participants were asked to self-report their physical health by using a 5-point Likert scale prior to attending the focus group $(22,23)$.

Participants were excluded from this study if they were not fluent in English (verbal, reading and writing) or if they were deemed unsuitable or unable to provide informed consent.

Studies on focus group size typically recommended group sizes between 6-12 participants $(9,12)$; however, several publications stated that groups composed of participants with age-related impairments should be sized down to encourage communication and ensure adequate participation by most member $(24,25)$. Quine \& Cameron (25) found the ideal group size of a focus group with older adults is between 5 and 6 participants. They described groups with four participants may have a risk of being less dynamic. With groups of more than 6 members, however, it can be challenging to ensure audibility and eye contact.

Participants were recruited from AGE-WELL NCE (Canada's largest network in technology and aging) and local hospitals (University Health Network) in Toronto, Canada by sending group emails and posting paper flyers.

A researcher (BY) reviewed the study with the potential participants who have initiated the contact and expressed their interest either on the phone or in person. The researcher explained the study, consent procedures and answer questions. Participants were also asked to self-report their physical ability to determine eligibility. In order to assess cognitive competency, the researcher will ask the participants questions related to the content of the consent form that was reviewed to ensure they fully understand and appreciate the study details. 
The consent form was reviewed with participants in person or over the phone, and the signed consent form was obtained before the commencement of data collection. Participants were informed that they may decide to withdraw from the study at any moment, without providing a reason. If a participant decided to withdraw or was withdrawn from the study, he/she would be asked whether their data could be retained and analyzed or whether they wished to have it destroyed.

\section{Data Collection}

All focus group sessions were audiotaped. Field notes were also taken during the discussion. Each focus group session took 90 minutes with a short break in the middle of the session. Two researchers were present in all three sessions. One researcher (BY) took field notes while the other researcher (CB) asked questions and facilitated the discussion between study participants.

During the focus group, the researcher first briefly introduced the study protocol while encouraging the participants to actively take part in the discussions by stressing that there was no right or wrong answer. The researcher then introduced the concept of frailty, and frailty phenotypes defined in a clinical frailty scale, the Fried's frailty index (26). The researcher subsequently introduced more clinical manifestations of frailty defined in the cycle of frailty proposed by Fried's et al. (27) and other behavior precursors related to frailty (28). In summary, the frailty criteria introduced include grip strength, weight, food intake, exhaustion, physical activities, immobilization and life space. Lastly, the researcher presented ten different types of technologies (Table 1), and explained how these technologies could be used to assess and monitor frailty at home based on the introduced frailty criteria. These technologies were chosen because they were readily available and have been commonly used for detecting the frailty criteria. The technologies were shown one by one to the participants with immediate discussion after presenting each technology before moving to the next one. Technologies were shown to each participant on an A4 paper or a shared computer screen (for the last online focus group session). The discussion included questions focused on understanding if participants would feel comfortable having their health measured by the technology. Questions from different angles were asked to achieve the goal of understanding their attitudes of the usefulness of the technologies. These angles include 1) the concerns or barriers of installing and using the presented technology in daily life at home, 2) the reasons participants like or dislike a particular technology, 3) what makes a particular technology more acceptable, and 4) participants' preferences in choosing technologies.

\section{Table 1 Technologies and the corresponding frailty criteria discussed in focus groups}




\begin{tabular}{|lll|}
\hline Technology & Frailty Criteria to be Detected & Where to Install \\
\hline Smart Watch & Physical Activity, Immobilization & Body worn \\
\hline Chair and Bed Sensor & Physical Activity, Immobilization & Chair and bed \\
\hline Motion Sensor & Physical Activity, Immobilization & On the wall of each room \\
\hline Standard Camera & Physical Activity, Immobilization & On the wall of each room \\
\hline Depth Camera & Physical Activity, Immobilization & One the wall of each room \\
\hline Door Sensor & Life Space & On the edge of a door and door frame \\
\hline Hand Dynamometer & Grip Strength & Portable \\
\hline Fridge Door Sensor & Food Intake & On the door of a fridge \\
\hline Smart Speaker & Food Intake & On a flat surface, e.g. a countertop \\
\hline Smart Speaker & Exhaustion & On a flat surface, e.g. a countertop \\
\hline Bathroom Scale & Weight & On the ground \\
\hline
\end{tabular}

\section{Data analysis}

Qualitative data from the recordings were transcribed verbatim. The transcripts were analyzed with an inductive thematic analysis $(29,30)$. This analysis started with open coding, writing notes, and headings in the original transcript. These headings were collected onto coding sheets and categories or themes were generated. After the open coding, the list of categories grouped under higher-order headings. Lastly, categories were abstracted in terms of formulating a general description of the research topic.

Subcategories with similar themes were grouped as categories, and categories were grouped as main categories (29).

\section{Results}

A total of 15 older adults at age of 65 and older were recruited in the study. Three focus group sessions were conducted with five participants in each session. There were 9 female and 6 male participants. Table 2 illustrates the demographic information of participants in three focus groups.

Three focus group sessions were held among which the first two sessions were in-person before the COVID-19 pandemic at the Intelligent Assistive Technology and Systems lab (IATSL) at the University of Toronto and the third session was held online using Microsoft Teams due to the pandemic.

\section{Table 2 Demographics of participants in focus groups}




\begin{tabular}{|c|c|c|c|c|c|}
\hline & ID & Age & Gender & Education level & Total years of education \\
\hline \multirow[t]{6}{*}{ Focus Group 1} & 1 & 84 & Female & High school & 12 \\
\hline & 2 & 70 & Male & High school & 12 \\
\hline & 3 & 85 & Female & Masters & 20 \\
\hline & 4 & 66 & Male & University & 17 \\
\hline & 5 & 74 & Male & University & 16 \\
\hline & Mean (SD) & $75.80(8.44)$ & & & $15.40(3.44)$ \\
\hline \multirow[t]{6}{*}{ Focus Group 2} & 6 & 65 & Female & University & 17 \\
\hline & 7 & 69 & Female & High school & 9 \\
\hline & 8 & 67 & Female & Masters & 19 \\
\hline & 9 & 71 & Female & College & 16.5 \\
\hline & 10 & 68 & Female & College & 17 \\
\hline & Mean (SD) & $68(2.24)$ & & & $15.70(3.87)$ \\
\hline \multirow[t]{6}{*}{ Focus Group 3} & 11 & 69 & Male & College & 15 \\
\hline & 12 & 73 & Female & Masters & 18 \\
\hline & 13 & 66 & Male & College & 16 \\
\hline & 14 & 74 & Male & Masters & 18 \\
\hline & 15 & 69 & Female & College & 15 \\
\hline & Mean (SD) & 70.20 (3.27) & & & $16.40(1.52)$ \\
\hline
\end{tabular}

In the findings, the attitudes and perspectives of participants on the technologies that could be potentially used for assessing and monitoring frailty were presented in four predominant areas: A) general attitude towards using the technology, B) concerns about the technologies, C) existing living habits or patterns related to use of the technologies, D) constructive suggestions related to the technologies. Tables $3,4,5$, and 6 provide an overview of the results for each area.

\section{A) General attitudes towards using the technology}

All participants reported an overall positive attitude towards each discussed technology except the standard camera. All participants showed their interest and believed there would be great benefits of 
using technologies to monitor health. Overall, participants were willing to install and try out the technologies in their homes. Table 3 shows a summary of the attitudes.

Table 3 Attitudes towards technologies potentially for assessing frailty 


\begin{tabular}{|c|c|c|c|c|}
\hline Technology & $\begin{array}{l}\text { Willingness } \\
\text { to Try }\end{array}$ & Attitudes & $\begin{array}{l}\text { Reasons for the } \\
\text { Attitudes }\end{array}$ & $\begin{array}{l}\text { Conditions for Acceptance } \\
\text { (if applicable) }\end{array}$ \\
\hline Smart Watch & Yes & $\begin{array}{l}\text { Positive } \\
\text { and } \\
\text { Negative }\end{array}$ & $\begin{array}{l}\text { Positive: } \\
\cdot \quad \text { Past experience } \\
\cdot \quad \text { Easy to wear } \\
\cdot \quad \text { Not easy to lose } \\
\cdot \quad \text { Light weight } \\
\text { Negative: } \\
\text { good health } \\
\text { No need because of } \\
\text { and use } \\
\cdot \quad \text { Simply no interest } \\
\cdot \quad \text { Can't see benefit }\end{array}$ & $\begin{array}{l}\text { Wearing locations } \\
\text { other than on the wrist }\end{array}$ \\
\hline $\begin{array}{l}\text { Chair and Bed } \\
\text { Sensor }\end{array}$ & Yes & $\begin{array}{l}\text { Positive } \\
\text { and } \\
\text { Slightly } \\
\text { Negative }\end{array}$ & $\begin{array}{l}\text { Positive: } \\
\text { Easy to use } \\
\text { something that the user } \\
\text { would forget it was there } \\
\text { Simple device } \\
\text { Negative: } \\
\text { No need because of } \\
\text { good health }\end{array}$ & $\begin{array}{l}\text { - Aesthetic appearance } \\
\text { Has heating function } \\
\text { function vibration }\end{array}$ \\
\hline $\begin{array}{l}\text { Motion } \\
\text { Sensor }\end{array}$ & Yes & Positive & $\begin{array}{l}\text { No need to wear } \\
\text { No need to } \\
\text { maintain }\end{array}$ & \\
\hline $\begin{array}{l}\text { Standard } \\
\text { Camera }\end{array}$ & No & Negative & $\begin{array}{l}\quad \text { Privacy invasive } \\
\text { No need because of } \\
\text { good health }\end{array}$ & $\begin{array}{l}\text { Only turned on during } \\
\text { limited period of time at } \\
\text { clinician's request } \\
\quad \text { Only installed at } \\
\text { specific areas in a home }\end{array}$ \\
\hline $\begin{array}{l}\text { Depth } \\
\text { Camera }\end{array}$ & Yes & Positive & None & \\
\hline Door Sensor & Yes & $\begin{array}{l}\text { Positive } \\
\text { and } \\
\text { Slightly } \\
\text { Negative }\end{array}$ & $\begin{array}{l}\text { Positive - None } \\
\text { Negative: }\end{array}$ & \\
\hline
\end{tabular}


Useless

No need

$\begin{array}{llll}\text { Hand } & \text { Yes } & \text { Positive } & \text { Simple to use }\end{array}$

Dynamometer

$\begin{array}{llll}\begin{array}{l}\text { Fridge Door } \\ \text { Sensor }\end{array} & \text { Yes } & \text { Positive } & \text { None } \\ \begin{array}{l}\text { Smart } \\ \text { Speaker }\end{array} & \text { Yes } & \begin{array}{l}\text { Positive } \\ \text { and } \\ \text { Slightly } \\ \text { Negative }\end{array} & \begin{array}{l}\text { Positive: } \\ \end{array} \\ & & \text { Past experience } & \text { Being fun to talk to } \\ & & \text { issue } & \text { Had exhaustion } \\ & & & \end{array}$

Negative:

- $\quad$ No need because of good health to

\begin{tabular}{|c|c|c|c|}
\hline \multirow{3}{*}{$\begin{array}{l}\text { Bathroom } \\
\text { Scale }\end{array}$} & \multirow[t]{3}{*}{ Yes } & \multirow{3}{*}{$\begin{array}{l}\text { Positive } \\
\text { and } \\
\text { Slightly } \\
\text { Negative }\end{array}$} & Positive: \\
\hline & & & Past experience \\
\hline & & & Parents had cancer \\
\hline & & & Negative: \\
\hline & & & $\begin{array}{l}\text { No need because of } \\
\text { good health }\end{array}$ \\
\hline
\end{tabular}

One participant could see that the technologies could track changes or progress of an individual's health conditions in a home by comparing the data collected by the technologies at different times. She also added "it's usually something else behind it that causes the hip to break it in the first place" to show that she thought the technologies can also be used to understand underlying causes of some adverse outcomes. The technologies can therefore prevent adverse outcomes such as fractions from happening by detecting early signs. Three other participants believed the data collected and interpreted by the technologies would be useful for both older adults themselves and clinicians to better understand their health and make a more informed decision.

"I think if technology like this or you know instruments like this are going to be useful for medical practitioners, then they would be valuable and I would use it because I think the more information you can give to your doctor the better off here. She's going to be when it comes to treating something that you 
might whether its frailty or whatever and if things like this can help improve the quality of people's lives as we age then I think it's a good thing".

Participants have also seen the technologies overall could benefit daily living of older adults. One participant thought the technologies could identify and inform potential problems in their daily living and advised what to do to live a healthier life. Another benefit that the participants have seen was that the more information that the technologies could collect and could be shared with their doctors, the better doctor could give them advice or diagnosis. Having the technologies at home monitoring their health, participants believed that it could promote aging in place with longer independence.

Eight participants across three focus groups indicated that they have had experience using a smart watch, such as a Fitbit. Two participants described the smart watch as easy to wear and was hard to lose. These comments came after the participants stated positive attitudes and can be seen as reasons for their positiveness. Similarly, when talking about a smart speaker, two participants indicated that they had spoken with Siri (a virtual assistant by Apple Inc.) on their smart devices while other participants simply thought they had no problem interacting with a smart speaker.

For chair and bed sensor mat, motion sensor and hand dynamometer, participants showed positive attitudes as one participant said, "It (the chair and bed sensor mat) looks like something that I almost forget it was there. It's not something I need set up or keep track of or restart or anything like that. It's very easy, a simple device." Other comments on these sensors include "it (the chair and bed sensor mat) seems like it would be very simple.", "I like this (hand dynamometer) actually, it's very simple.", and "it's (the motion sensor) not anything I have to wear or maintain.".

Participants' positive attitudes were also built on certain conditions. In other words, participants would become more acceptable to certain technologies if certain conditions were met. These conditions fall into the following categories: 1) wearing location of a wearable sensor, 2) health conditions of a specific population, 3) installation locations of technologies, 4) customization of monitoring period, and 5) functions of technologies.

\section{1) Wearing location of a wearable sensor}

An interesting finding from this focus group is non-wrist-worn wearable sensors such as necklace sensor, or ankle sensor might be more appropriate for certain older population to accommodate their special conditions such as dermatitis. One participant who has been a Fitbit user indicated that she had dermatitis and did not like to wear things on her wrist. Instead of wearing a Fitbit watch on her wrist, she has been using a Fitbit clip which can be clipped to her clothes to monitor her health. Another participant stated "...also something that you could attach to your ankle or something.", whereas the third participant liked the sensor to be worn as a necklace by saying "something like a necklace... you know like wearing a necklace that would detect some frailty things and make it attractive enough that you can just like wear it as a necklace or something like that." 


\section{2) Health conditions of a specific population}

Participants believed that people with certain health issues could become more inclined to use technologies to monitor their health. People with a high risk of falls, who are currently in rehabilitation, or who are currently living alone, could be keener and more acceptable to use technologies. They may even consider the use of invasive devices, such as a standard camera, if their health conditions changed.

\section{Standard camera}

One participant commented on her opinion about the standard camera as "It's probably good for somebody that's in recovery. And being in their bedroom in recovery. And then you know, their physio therapist comes in and their occupational therapist comes in, and so you have to stand up five times today. You gotta roll over, sit up, stand up."

Two participants who indicated that the standard camera was invasive also expressed that this could change with the decline in their health by saying "This may change if my situation, my healthy situation, my problem changed dramatically. In that case, boundary will be moved a little bit." and "Perhaps if I was in a different place in terms of my frailty, I might be more open to it".

\section{Chair and bed sensor mat}

One participant suggested that the sensor mat could be useful for people with lower back issues as the mat could remind people to change their postures if they stayed in a sedentary position for too long. "I think it's a good you know, having that kind of reminder for some people with probably some lower back issues because it's you know I was that long lying down, right? You know, they will think, all well that's I got to change that but if they have if their beds telling the truth or their chair is telling the truth back. They can't argue."

Another participant indicated that the mat could be useful for caregivers caring for someone who could not leave the bed.

"If someone is declining so much that they can't get out of bed or they have to, then this might be useful for a caregiver to record how many hours somebody is lying in one position and they need to be turned so they don't develop bed sores. It could be useful to a caregiver for somebody who's really declined a lot. So I do see some additional plus possible pluses for this".

\section{3) Installation locations of technologies}

\section{Standard camera}


Four participants expressed a similar idea that they would become more open to use a standard camera if the camera was only installed at a certain location or a public space in their homes, such as a living room or a dining room. "I feel invasive unless it (the camera) was only kept to say one certain room. But I wouldn't feel good about it being in a bedroom or washroom", said one participant. Another example that the installation location could make the camera more acceptable was to have the camera installed on a fridge to monitor how a person uses a fridge, or the time the person eats for the purpose of monitoring food intake.

\section{Door sensor for food intake}

Participants were not convinced that the door sensor installed only on the fridge was useful to measure the food intake. However, by adding the door sensors on doors of kitchen cabinet where food is stored, participants would think that the device could become more practical.

\section{4) Customization of monitoring period}

Participants would not object to a standard camera if the camera was turned on only during a specific period just for frailty assessment at a doctor's request and switched off outside the requested monitoring period. For example, one participant stated, "I'm gonna enable this for you between 10 in the morning and 11 o'clock tomorrow so you can watch how I walk. That would make sense. But 24 hours a day constantly. No, I'm not comfortable with it".

\section{5) Functions of technologies}

A technology with assistive functions could promote its acceptance rate. For example, besides the original function of asking questions for self-report exhaustion and food intake, participants found it would be more favorable if a smart speaker can also remind a person to take medication, go out for a walk or measure the grip strength, like one participant stated, "I think there is good use of additional, you know, not only ask somebody eat, but also remind somebody to take their medication." Three more participants suggested adding a built-in reminder function such as a timer and an alarm to the chair sensor mat and the hand dynamometer.

"if you're in a sedentary job, it's good to get reminded to get up and go for a walk".

"I think you'd have to get in your day timer something to remind you to do it (grip strength test using hand dynamometer)".

"To have a built-in alarm of any type to alert a senior that, let's say 30 minutes or an hour had passed. They should make an effort to stand up... The problem is that people can get too sedentary that can be 
alarming sometimes to realize how long you'v been sitting in one spot you know, without moving and I'm finding as I get older than I'm more and more getting... You could be watching television for all night".

Although participants had no problem installing and trying out the technologies, they questioned the usefulness of the technologies based on their health conditions, needs and added values. To be specific, participants mentioned that they did not see a need to use the technology to monitor their health when they were still healthy and active. Participants indicated that the chair and bed sensor mat would not be useful for them because they were still quite active in their daily life.

After stated "Yeah, I feel comfortable using it.", the same participant followed by saying "I don't think I am at a stage where I need to track this stuff (sedentary behavior). I am fairly active. So practically, you know from a practical point of view, I don't see a use currently."

"I can't really see at this point and possibly that in the future."

"I mean It'd be okay to have one (weight scale) I guess. But I don't see it as being ... unless the person's got a real problem, you know, with health issues related to obesity."

"I have a scale now and I wouldn't mind having one like this in the future to detect weight loss, you know, especially with cancer with my parents. That was like a big thing, keeping track of the weight loss. They got more frail."

Limited added value for some technologies was also reported. Some participants gave up using a technology such as a smart watch that they used to use due to limited to none contribution that the technology added to their health. "It didn't contribute with anything to my wellbeing. I am still active, I basically know how many steps I take and all that.", said one participant. Another participant felt the smart watch is simply no attraction by stating "I first started to investigate this kind of thing earlier, but stopped doing it. Just no attraction to me." Although participants stated they had no problem wearing a smart watch, they just could not find a need for it like a participant said "I wouldn't have any trouble wearing it, but it's just em, what it's telling me I don't have any use for. I don't need to know."

\section{B) Concerns about the technologies}

The participants from all three groups voiced several concerns related to the presented technologies. The concerns are summarized in Table 4. These concerns belong to the following categories:

- Privacy

- Adherence

- Appearance

- Technical concerns

- Others 


\section{Privacy}

The standard camera received the most outstanding pushback. Fourteen participants reported that they did not feel comfortable having the camera installed in their homes and being monitored 24/7. They felt the use of the camera in their homes was intrusive and violating their privacy. Some of the participants stated, "It doesn't fit well with me. I like my privacy.", "I wouldn't want to feel that somebody was watching my activities.", "I feel invasive.", "No, no use for it (standard camera) whatsoever other than security outside, that'd be fine. But inside those there's no use at all to me.", and "I would not like to use it. I will I would consider it an invasion of privacy."

On the contrary, all participants were more positive towards a depth camera, which would not reveal any clear image of a person but only the silhouette of a person. Participants felt more appropriate and more acceptable to this approach. Participants stated, "I think it (depth camera) is an improvement over a previous technology (standard camera) regarding privacy.", "I would be much more comfortable with this (depth camera), and I wouldn't mind I don't think if it was in the bedroom. You can't see what I'm wearing, and you can't see my face, you don't' know anything about my body, other than the outline. Yeah. I wouldn't have an issue.", "It (depth camera) allows for privacy. Yah, on the other hand, the camera (depth camera) provides information in addition of the individual, it may record the person is not dressing properly, and it could be a further clue of deterioration for the clinician. So, I find a balance between privacy and clinicians to assessing deeply than with a regular camera.", and "My face is not seen. So, what's my problem? I don't have any problem."

\section{Adherence}

The second most mentioned concern is the adherence to the use of technology, especially for body-worn technologies like the smart watch. Participants mentioned that the memory could be an issue for the adherence to the use of a smart watch. This is because people could forget to put it on in the case of urgency or had trouble remembering to put it on. One participant stated as a general comment for all technologies, "So everything that's automated I would prefer over something that I have to interact."

Skepticism about technologies could be another reason for poor adherence, particularly for body-worn technologies. Like one participant said, "I would like to try but it'll probably go the way (giving up) of all the other things that l've tried." This participant did not think the technologies would work so he gave up using them. Three more participants also shared that they had stopped using a smart watch that they used to use because they did not think it would work or attractive. "It didn't contribute to anything.", said one participant. "I first started to investigate this kind of thing earlier, but stopped doing it. Just no attraction to me.", said another participant.

\section{Appearance}


Participants would be more likely to use technology if the technology is aesthetically pleasing. Two participants stated, "I think that something like that (chair and bed sensor mat) is probably very practical for a senior, especially if they could put a pillow over top of it to make it a little bit less, more cosmetic and less obtrusive." and "But, aesthetically, I think this is I can't see it (chair and bed sensor mat) getting used in a practical point of view until somebody became so old that they really didn't care what, like this, to have this sitting in the middle of their living room or something. I think, you know, uh, I don't see this is something that somebody will use in the long term."

\section{Technical concerns}

The concerns around the technical aspects of the technologies include the data accuracy, operating interface, interaction with the technologies, and power supply. Participants across all three focus groups questioned about whether a motion or fridge door sensor could differentiate people living in the same house as people may live with their spouses, children, or roommates. Three participants stated:

"My grandson comes over and the door (fridge door) is open every minute. They're in and out all the time."

"I rent a room from a friend of mine who has a Filipino girlfriend and three little Filipino girls. And the fridge is open five hundred times a day. I might open the fridge three times a day. They open it five hundred times a day. So, for me too it's not going to detect anything from for me."

"It (motion sensor) cannot differentiate. So, if you live with somebody else or have guests over, it would pick up their activity too so that's kind of not beneficial."

The locations for food storage could also affect data accuracy. Participants expressed their concerns as follows:

"There's very little stuff in my fridge other than water and ginger ale", "that's not the only place you get food is out of the fridge."

"That wouldn't work for nutrition, like if I open the door to get a bottle of water, that's not nutrition."

"You can prepare meals from your fridge. But you could also make a sandwich and a soup and heat it up. You're still eating but you are not using your fridge."

The concern over operating interface of the technologies was focused on the camera. One participant said she would find it helpful if the technology could present to her visually what data of hers would be shared with her clinician.

"It would really help me a lot if, as part of this presentation, you had a second photo, that says this is what the clinician or the person on the end of the viewing can actually see." 
Technologies such as motion sensor, door sensor, or camera do not require its user to operate, therefore, no concerns about the interaction with the technologies. However, participants were concerned about interaction with the smart speaker, which required its user to answer questions verbally and periodically. One participant asked, "What if I missed it (a smart speaker asking questions)."

The last concern was about the power supply of the chair and bed sensor, two participants expressed opposite concerns with one preferring battery power and another preferring plug-in power supply.

\section{Others}

Other concerns include feeling guilty ("I don't know if I'd use that, that would make me feel guilty if I use something like that because then I would know how sedentary I am."), cost ("All of this technology I have an issue with a lot of seniors I know are living on very low incomes and they have like no extra money to spend on even a Fitbit').

Table 4 Concerns about the technologies for assessing frailty at home

\begin{tabular}{|ll|}
\hline Technology & Concerns \\
\hline Smart Watch & Poor adherence \\
\hline $\begin{array}{l}\text { Chair and Bed } \\
\text { Sensor }\end{array}$ & $\begin{array}{l}\text { Not aesthetically pleasing, feeling guilty, Not washable, battery or plug-in } \\
\text { power supply }\end{array}$ \\
\hline Motion Sensor & Inaccurate data \\
\hline Standard Camera & Privacy invasive \\
\hline Depth Camera & None \\
\hline Door Sensor & Inaccurate data \\
\hline $\begin{array}{l}\text { Hand } \\
\text { Dynamometer }\end{array}$ & Poor adherence, needs reminder \\
\hline Fridge Door Sensor & Inaccurate data \\
\hline Smart Speaker & Interaction \\
\hline Bathroom Scale & None \\
\hline
\end{tabular}

\section{C) Existing living habits or patterns related to the use of the technologies}


Participants also shared their living habits or patterns that could influence the use of the technologies. These habits or patterns were centered around three areas: 1) food intake, 2) physical activities, and 3) weight. For food intake, we found a diverse pattern ranging from the habits of food intake that had not changed too much for decades to experiencing a gradual change of eating habits, a significant change in eating habits. Additionally, some participants reported they cannot cook anymore and rely on the microwave oven to heat food only, while others mentioned they have healthy and balanced food intake. Regarding the physical activities, several participants reported that they "never sit, never had a sitting job" or walk a lot because of the nature of their jobs (e.g. a chef, or most clients are in downtown where walking might be better than driving), whereas other participants reported having more sedentary behavior than they used to have.

"Yeah, I sit a lot more than I used to."

Moreover, the small size of an apartment limits participants' moving around at home and thus fewer physical activities.

"I don't move around too much haha I just live in an apartment.", said one participant.

For weight, participants reported diverse weight loss. Some reported unintentional weight loss whereas others reported constant weight or even weight gain.

Table 5 Existing living habits or patterns as related to frailty criteria and the technologies for assessing frailty 


\begin{tabular}{|c|c|c|}
\hline Technology & Frailty Criteria & Related Living Habits or Patterns \\
\hline \multirow[t]{2}{*}{ Smart Watch } & \multirow{2}{*}{$\begin{array}{l}\text { Physical Activity, } \\
\text { Immobilization }\end{array}$} & Regular indoor bike riding \\
\hline & & . $\quad$ Much outdoor walking for work \\
\hline $\begin{array}{l}\text { Chair and Bed } \\
\text { Sensor }\end{array}$ & $\begin{array}{l}\text { Physical Activity, } \\
\text { Immobilization }\end{array}$ & Few to no sitting due to work \\
\hline \multirow[t]{2}{*}{ Motion Sensor } & \multirow{2}{*}{$\begin{array}{l}\text { Physical Activity, } \\
\text { Immobilization }\end{array}$} & Has roommates \\
\hline & & . Small apartment \\
\hline Standard Camera & $\begin{array}{l}\text { Physical Activity, } \\
\text { Immobilization }\end{array}$ & Wear shorts at home \\
\hline Depth Camera & $\begin{array}{l}\text { Physical Activity, } \\
\text { Immobilization }\end{array}$ & None \\
\hline Door Sensor & Life Space & Open and close door without going out \\
\hline $\begin{array}{l}\text { Hand } \\
\text { Dynamometer }\end{array}$ & Muscle Strength & None \\
\hline $\begin{array}{l}\text { Fridge Door } \\
\text { Sensor }\end{array}$ & Food Intake & Has roommates \\
\hline \multirow[t]{7}{*}{ Smart Speaker } & \multirow[t]{7}{*}{ Food Intake, Exhaustion } & Never eat too much \\
\hline & & Significantly change in eating habits \\
\hline & & Gradual change in eating habits \\
\hline & & . $\quad$ Eat the same always \\
\hline & & Eat healthy \\
\hline & & Can't cook \\
\hline & & . $\quad$ Microwave cooking only \\
\hline \multirow[t]{3}{*}{ Bathroom Scale } & \multirow[t]{3}{*}{ Weight } & . $\quad$ Constant weight for years \\
\hline & & $\begin{array}{l}\text { - Unintentional weight loss in the past nine } \\
\text { years }\end{array}$ \\
\hline & & . Weight gain \\
\hline
\end{tabular}

\section{D) Constructive suggestions related to the technologies}

We have surprisingly found that participants have given very constructive suggestions during the focus group discussion. These suggestions were about other potential uses of the discussed technologies although some of these suggestions were not directly related to frailty assessment. Participants 
suggested that there could be more ways to use a smart speaker in addition to assessing self-report exhaustion. For example, older adults could communicate with the smart speaker for mitigating social isolation. Moreover, the smart speaker that was used to ask exhaustion-related questions only could gain more interest from users if it offers added features such as playing music, notifying lab results remotely and so on. Participants stated that besides collecting food intake information from the smart speaker, it could also suggest to users what to eat based on the food intake information collected from the user. In addition, participants thought the smart speaker could also ask questions about users' movements and physical activity.

Technologies would become more acceptable if they could provide more functionalities while they are performing the core functions for frailty assessment, just like what a participant said, "Like if it (bed and chair sensor mat) gets warm and vibrates, I'd love one". Another participant also said, "If it (door sensor) had an alarm on it like a beeping sound if you were concerned about somebody that's going out on their own. You know like your spouse, they'd be getting some cognitive disorientation. Or they're taking medications and it's making them a little wonky you know, sort of like if they go and they are just going to the store to get milk and you hear the door open if this is going to have like a buzzer on it and close so you have: ah they're going and you're like "you're on the clock" because you know how long it's gonna take for them to go to the store and get back".

The safety of people with cognitive decline or dementia was frequently mentioned during the group discussion. Participants could see extra benefits of technologies if technology could provide reminders to individuals with cognitive decline when users forget to turn off a stove, to feed themselves, to close a door, or has left home for a long time.

Once powered on, the technologies for assessing frailty discussed in this study are designed to operate automatically and continuously in-home settings without much manual operation needed from the users such as turning on and off every day, especially for the technologies that are embedded into the environment such as camera, motion, door, and pressure sensors. The continuous operating technologies at home raised concerns from participants, however, the majority of the concerns came from the camera that has been mentioned in the previous section. The participants then in turn made suggestions about if the technology can be switched from continuous monitoring to be turned on and off only at the doctor's request.

\section{Table 6 Constructive suggestions related to the technologies for assessing frailty}




\begin{tabular}{|c|c|}
\hline Technology & Suggestions \\
\hline Smart Watch & Reminder for completing certain amount of daily activity \\
\hline $\begin{array}{l}\text { Chair and Bed } \\
\text { Sensor }\end{array}$ & More functions including getting warm and vibration \\
\hline Motion Sensor & Safety reminder for people with cognitive decline or dementia \\
\hline \multirow{4}{*}{$\begin{array}{l}\text { Standard } \\
\text { Camera }\end{array}$} & Use in certain rooms \\
\hline & Can be turned on and off by doctors \\
\hline & Use outside of the home \\
\hline & Use for individuals in recovery and monitor compliance to doctor's plan \\
\hline Depth Camera & None \\
\hline Door Sensor & Safety reminder for people with cognitive decline or dementia \\
\hline \multirow{3}{*}{$\begin{array}{l}\text { Hand } \\
\text { Dynamometer }\end{array}$} & Reminder for use \\
\hline & Strength test for other parts of the body \\
\hline & Bone density test \\
\hline $\begin{array}{l}\text { Fridge Door } \\
\text { Sensor }\end{array}$ & Reminder for food intake for people with cognitive decline or dementia \\
\hline \multirow[t]{3}{*}{ Smart Speaker } & Reminder for taking medication \\
\hline & Can be used to mitigate social isolation \\
\hline & $\begin{array}{l}\text { Engage older adults and avoid resistance to technology by building in more } \\
\text { functions such as playing music }\end{array}$ \\
\hline $\begin{array}{l}\text { Bathroom } \\
\text { Scale }\end{array}$ & None \\
\hline
\end{tabular}

\section{Discussion And Implications}

This study identified four areas regarding the use of technologies for assessing frailty at home: A) general attitude towards using the technology, B) concerns about the technologies, C) existing living habits or patterns related to using the technologies, D) constructive suggestions related to the technologies. Participants generally have no problem with installing and using the technologies presented except for the standard camera. The factors that could affect a technology's acceptability include past user experience, easy to use and maintain, not easy to lose, lightweight, functionality, and clinician's request. Privacy is the biggest concern for the rejection of the standard camera. Older adults often avoided or stopped using technology due to privacy and security concerns or violations, which also affect their intentions to purchase and use emerging technologies (31). This study shows that their attitudes would change if privacy issues are no longer a concern. When technology is designed and 
developed, it is important for technology designers and developers to protect older adults' privacy in order to enhance the adoption of developed technologies.

The acceptance of the standard camera could change if used under certain conditions. Specifically, older adults could become more acceptable to camera monitoring if the camera is only used in a certain area of a home (i.e., living room) and/or when a person's health conditions change dramatically. On one hand, participants realize that the vision-based technologies (i.e., a camera) have advantages over wearable and other furniture embedded sensors like motion or door sensors for gait and posture analysis, and fall detection, etc. When a camera is used under the above conditions, the benefits a person gets would overweigh the privacy he or she gives up, therefore users could become more open to this approach for inhome monitoring. On the other hand, when a person's health conditions change dramatically, participants believe that the person would care less privacy and become more motivated to try technologies including a camera as the primary goal of the person has become maintaining and improving health and safety. For non-intrusive technologies such as motion or door sensors presented in this study, participants were skeptical about the effectiveness of certain applications. For instance, although the fridge door sensor was well accepted to be installed at participants' homes, participants were skeptical about whether the sensor could accurately measure food intake and therefore nutrition as the sensor is not capable of identifying who uses the fridge and what food is taken. Also, as one fridge door sensor can only be installed on one fridge door and only monitoring the open and close of that door, food taken activities from other places in a kitchen could not be monitored. Multiple sensors should be installed in different areas that may contain food to have a more complete detection of food intake.

The findings about living habits may inspire technology developers, clinicians and older adults themselves ways they should consider when they develop or use technologies. As an example, the choice of technologies and the interpretation of results could be different for someone who only uses microwave oven than someone who uses both stove and microwave oven to cook. For someone who "never sit" because of work, the choice of technologies and interpretation of results should consider this factor. For participants share different situations at home for food intake, such as intaking microwave food only, or roommates sharing a kitchen, which could affect the data accuracy of technology, therefore, no single location of monitoring such as the fridge could accurately detect all food intake or even close. An improved way of developing technology for detecting food intake is to monitor not only the fridge but also the kitchen cabinet that contains food as well. Identification technology such as Radio Frequency Identification (RFID) or vision-based technology should be integrated in a kitchen that used by multiple residents in order to count the use of the fridge by the person of interest only. Similarly, for monitoring the intensity of physical activity by motion sensor, the sensor that could not identify a specific person could be installed in private rooms where only the older adult being monitored would use. Then it would be interesting to further study whether the activity data collected from only private areas in a home could contribute to frailty assessment. If needed, the identification technologies such as camera or RFID can be added in public areas to get more valuable data. Overall, individualized technology design and development for assessing frailty at home should be considered. 
The findings in this study could also influence the form factor (e.g. size, shape, appearance, etc.) and functionality of a technology for assessing frailty at home. For example, the design of a wearable sensor should consider having a variety of form factors to meet different needs of older population based on their personal preferences and health conditions. Moreover, a technology that has more useful add-on functions which might not necessarily be clinical functions such as a warming or vibration function in a bed and chair sensor mat could improve adherence of using the technology, which in turn would enable long-term data collection about sedentary behavior to better predict frailty. Similarly, changing the way how a technology works at home such as enabling turning on and off for a technology for a specific period with a clinician's request instead of continuous monitoring 24/7 could turn the technology more favorable and therefore longer used by its user.

\section{Conclusions}

This study focuses on understanding the attitudes and perceptions of older adults on several technologies that could potentially be used to assess frailty in home settings. Participants generally have positive attitudes towards allowing the technologies to be installed and used at their home. Some technologies such as cameras were found to be more acceptable if used under certain conditions such as installation locations, monitoring period and/or with specific populations. However, questions and concerns still remain. These questions and concerns were around privacy, adherence, appearance, and technical aspects. The study also found the living habits or patterns of older adults could affect the design and use of technology. Lastly, many valuable suggestions regarding the use of technologies have been made by participants. These suggestions might not be directly related to frailty assessment, however, if considered, the acceptance and feasibility of the technologies could be improved.

\section{List Of Abbreviations}

RFID - Radio Frequency Identification

\section{Declarations}

All methods were carried out in accordance with relevant guidelines and regulations.

\section{Ethics approval and consent to participate}

This study protocol was approved by University of Toronto Research Ethics Board (protocol number 37993). Written consents to participate have been obtained from each participant prior to the study.

\section{Consent for publication}

Consent for publication was obtained from each participant during the consent process.

\section{Availability of data and materials}


The datasets used and/or analyzed during the current study are available from the corresponding author on reasonable request.

\section{Competing interests}

The authors declare that they have no competing interests.

\section{Funding}

The project is funded by AGE-WELL NCE (Aging Gracefully across Environments using Technology to Support Wellness, Engagement and Long Life NCE Inc.) - Networks of Centres of Excellence of Canada.

\section{Authors' contributions}

The study was designed by the first author ( $\mathrm{CB}$ ) and the third author (AH). The other authors reviewed the study design. $C B$ was the main interviewer in all three focus group sessions. He also transcribed the audio recordings from the third focus group session, analyzed the transcribed data, and drafted the manuscript. The second author (BY) was the point of contact for recruiting study participants and managed the study documents. She was also the notetaker in all three focus group sessions, and made major contribution in revising the manuscript. AH transcribed the audio recordings from the first two focus group sessions. AM made major contribution in reviewing the study protocol for Research Ethics Board, revising the manuscript and providing academic and financial sponsorship to the study. All authors read and approved the final manuscript.

\section{Acknowledgements}

The authors acknowledge the participation of all participants in the focus groups.

\section{Authors' information}

University of Toronto and KITE Research, Toronto Rehabilitation Institute, University Health Network, Toronto, Canada Chao Bian, Bing Ye, \& Alex Mihailidis

Department of Psychology, Utrecht University, Utrecht, The Netherlands Anna Hoonakker

\section{References}

1. Morley JE, Vellas B, Abellan van Kan G, Anker SD, Bauer JM, Bernabei R, et al. Frailty consensus: A call to action. J Am Med Dir Assoc [Internet]. 2013 Jun;14(6):392-7. Available from: https://linkinghub.elsevier.com/retrieve/pii/S1525861013001825

2. Collard RM, Boter H, Schoevers RA, Oude Voshaar RC. Prevalence of frailty in community-dwelling older persons: A systematic review. J Am Geriatr Soc [Internet]. 2012 Aug;60(8):1487-92. Available from: http://doi.wiley.com/10.1111/j.1532-5415.2012.04054.x 
3. Basic D, Shanley C. Frailty in an older inpatient population. J Aging Health [Internet]. 2015 Jun 19;27(4):670-85. Available from: http://journals.sagepub.com/doi/10.1177/0898264314558202

4. Buckinx F, Rolland $Y$, Reginster $J-Y$, Ricour $C$, Petermans $J$, Bruyère 0 . Burden of frailty in the elderly population: perspectives for a public health challenge. Arch Public Heal [Internet]. 2015 Dec 10;73(1):19. Available from: https://archpublichealth.biomedcentral.com/articles/10.1186/s13690015-0068-X

5. Schwenk M, Mohler J, Wendel C, D"Huyvetter K, Fain M, Taylor-Piliae R, et al. Wearable sensor-based in-home assessment of gait, balance, and physical activity for discrimination of frailty status: Baseline results of the Arizona Frailty Cohort Study. Gerontology [Internet]. 2015;61(3):258-67. Available from: https://www.karger.com/Article/FullText/369095

6. Pippa E, Mporas I, Megalooikonomou V. Feature selection evaluation for light human motion identification in frailty monitoring system. In: Proceedings of the International Conference on Information and Communication Technologies for Ageing Well and e-Health [Internet]. SCITEPRESS Science and and Technology Publications; 2016. p. 88-95. Available from: http://www.scitepress.org/DigitalLibrary/Link.aspx?doi=10.5220/0005912200880095

7. Bian $\mathrm{C}, \mathrm{Ye} \mathrm{B}, \mathrm{Chu} \mathrm{CH}$, McGilton KS, Mihailidis A. Technology for home-based frailty assessment and prediction: A systematic review. Gerontechnology [Internet]. 2020 Nov 2;19(3):1-13. Available from: https://journal.gerontechnology.org/currentlssueContent.aspx?aid=2931

8. Riemer-Reiss ML, Wacker RR. Factors associated with assistive technology discontinuance among individuals with disabilities. J Rehabil [Internet]. 2000 Jul 1;66(3):44. Available from: http://myaccess.library.utoronto.ca/login? qurl=https\%3A\%2F\%2Fwww.proquest.com\%2Fdocview\%2F1310699007\%3Faccountid\%3D 14771

9. Wong LP. Focus group discussion: a tool for health and medical research. Singapore Med $J$ [Internet]. 2008 Mar;49(3):256-60; quiz 261. Available from: http://www.ncbi.nlm.nih.gov/pubmed/18363011

10. Bastien JMC. Usability testing: a review of some methodological and technical aspects of the method. Int J Med Inform [Internet]. 2010 Apr;79(4):e18-23. Available from:

https://linkinghub.elsevier.com/retrieve/pii/S1386505608002098

11. Czaja SJ, Lee CC. The impact of aging on access to technology. Univers Access Inf Soc [Internet]. 2007 Mar 19;5(4):341-9. Available from: http://link.springer.com/10.1007/s10209-006-0060-x

12. Powell RA, Single HM. Focus groups. Int J Qual Heal Care [Internet]. 1996;8(5):499-504. Available from: https://academic.oup.com/intqhc/article-lookup/doi/10.1093/intqhc/8.5.499

13. Demiris G, Hensel BK, Skubic M, Rantz M. Senior residents' perceived need of and preferences for "smart home" sensor technologies. Int J Technol Assess Health Care [Internet]. 2008 Jan 24;24(01):120-4. Available from: http://www.journals.cambridge.org/abstract_S0266462307080154

14. Courtney KL. Privacy and senior willingness to adopt smart home information technology in residential care facilities. Methods Inf Med [Internet]. 2008 Jan 19;47(01):76-81. Available from: http://www.thieme-connect.de/DOI/DOI?10.3414/ME9104 
15. Mitzner TL, Boron JB, Fausset CB, Adams AE, Charness N, Czaja SJ, et al. Older adults talk technology: Technology usage and attitudes. Comput Human Behav [Internet]. 2010 Nov;26(6):1710-21. Available from: https://linkinghub.elsevier.com/retrieve/pii/S0747563210001925

16. Thompson HJ, Thielke SM. How do health care providers perceive technologies for monitoring older adults? In: 2009 Annual International Conference of the IEEE Engineering in Medicine and Biology Society [Internet]. IEEE; 2009. p. 4315-8. Available from: http://ieeexplore.ieee.org/document/5333599/

17. Kononova A, Li L, Kamp K, Bowen M, Rikard R, Cotten S, et al. The use of wearable activity trackers among older adults: Focus group study of tracker perceptions, motivators, and barriers in the maintenance stage of behavior change. JMIR mHealth uHealth [Internet]. 2019 Apr 5;7(4):e9832. Available from: https://mhealth.jmir.org/2019/4/e9832/

18. Epstein I, Aligato A, Krimmel T, Mihailidis A. Older adults' and caregivers' perspectives on in-home monitoring technology. J Gerontol Nurs [Internet]. 2016 Jun 1;42(6):43-50. Available from: http://www.healio.com/doiresolver?doi=10.3928/00989134-20160308-02

19. Lindqvist E, PerssonVasiliou A, Hwang AS, Mihailidis A, Astelle A, Sixsmith A, et al. The contrasting role of technology as both supportive and hindering in the everyday lives of people with mild cognitive deficits: a focus group study. BMC Geriatr [Internet]. 2018 Dec 17;18(1):185. Available from: https://bmcgeriatr.biomedcentral.com/articles/10.1186/s12877-018-0879-z

20. Ozanne A, Johansson D, Hällgren Graneheim U, Malmgren K, Bergquist F, Alt Murphy M. Wearables in epilepsy and Parkinson's disease-A focus group study. Acta Neurol Scand [Internet]. 2018 Feb;137(2):188-94. Available from: http://doi.wiley.com/10.1111/ane.12798

21. Le T, Reeder B, Yoo D, Aziz R, Thompson HJ, Demiris G. An evaluation of wellness assessment visualizations for older adults. Telemed e-Health [Internet]. 2015 Jan;21(1):9-15. Available from: https://www.liebertpub.com/doi/10.1089/tmj.2014.0012

22. Keith NR, Clark DO, Stump TE, Miller DK, Callahan CM. Validity and reliability of the self-reported physical fitness (SRFit) survey. J Phys Act Heal [Internet]. 2014 May;11(4):853-9. Available from: https://journals.humankinetics.com/view/journals/jpah/11/4/article-p853.xml

23. Vagias WM. Likert-type scale response anchors. Clemson Int Inst Tour Res Dev Dep Park Recreat Tour Manag Clemson Univ. 2006;

24. Barrett J, Kirk S. Running focus groups with elderly and disabled elderly participants. Appl Ergon [Internet]. 2000 Dec;31(6):621-9. Available from: https://linkinghub.elsevier.com/retrieve/pii/S0003687000000314

25. Quine S, Cameron I. The use of focus groups with the disabled elderly. Qual Health Res [Internet]. 1995 Nov;5(4):454-62. Available from: http://journals.sagepub.com/doi/10.1177/104973239500500406

26. Fried LP, Tangen CM, Walston J, Newman AB, Hirsch C, Gottdiener J, et al. Frailty in older adults: evidence for a phenotype. Journals Gerontol Ser A Biol Sci Med Sci [Internet]. 2001 Mar 
1;56(3):M146-57. Available from: https://academic.oup.com/biomedgerontology/articlelookup/doi/10.1093/gerona/56.3.M146

27. Xue QL, Bandeen-Roche K, Varadhan R, Zhou J, Fried LP. Initial manifestations of frailty criteria and the development of frailty phenotype in the women's health and aging study II. Journals Gerontol Ser A Biol Sci Med Sci. 2008;63(9):984-90.

28. Xue QL. The Frailty Syndrome: Definition and Natural History. Clin Geriatr Med. 2011;27(1):1-15.

29. Onwuegbuzie AJ, Dickinson WB, Leech NL, Zoran AG. A qualitative framework for collecting and analyzing data in focus group research. Int J Qual Methods [Internet]. 2009 Sep 1;8(3):1-21. Available from: http://journals.sagepub.com/doi/10.1177/160940690900800301

30. Elo S, Kyngäs H. The qualitative content analysis process. J Adv Nurs [Internet]. 2008 Apr;62(1):10715. Available from: http://doi.wiley.com/10.1111/j.1365-2648.2007.04569.x

31. Frik A, Nurgalieva L, Bernd J, Lee JS, Schaub F, Egelman S. Privacy and Security Threat Models and Mitigation Strategies of Older Adults. In: Proceedings of the Fifteenth USENIX Conference on Usable Privacy and Security. USA: USENIX Association; 2019. p. 21-40. (SOUPS'19). 